\title{
Políticas públicas decorrentes da mudança no Código Florestal
}

Public policy derived from the change in the Forest Code

\section{Politiques publiques relatives au changement dans le Code Forestier \\ Políticas públicas resultantes del cambio en el Código Forestal}

\author{
Jandira Turatto Mariga ${ }^{1}$ \\ Aloisio Ruscheinsky ${ }^{2}$ \\ Recebido em 21/11/2016; revisado e aprovado em 15/04/2017; aceito em 30/04/2017 \\ DOI: http://dx.doi.org/10.20435/inter.v18i3.1441
}

\begin{abstract}
Resumo: Uma política pública de meio ambiente tem por meta a proteção dos bens naturais em colaboração com a sociedade. Este artigo apresenta uma discussão sucinta sobre a configuração das políticas públicas de meio ambiente. Faz uma breve discussão dos Códigos Florestais brasileiros, das ações adotadas pelo Governo Federal e pelo Governo do Estado do Paraná no tocante à implementação das políticas públicas decorrentes de meio ambiente.
\end{abstract}

Palavras-chave: Código Florestal; políticas públicas; meio ambiente.

Abstract: This research aims at studying public policy concerning the environment, whose goal is protecting natural resources with the society assistance. Thus, this paper presents a brief discussion on the setting of public policy of the environment. There is also a brief argument concerning the Brazilian Forest Codes, the actions taken by the Federal and Paraná State Governments regarding the implementation of public policies derived from the environment.

Key words: Forest Code; public policy; environment.

Résumé: Cette recherche vise à étudier les politiques publiques relatives à l'environnement qui vise à la protection des ressources naturelles avec la coopération de la société. Ainsi, cet article présente une brève discussion sur le cadre de l'environnement des politiques publiques., aussi bien que une brève analyse concernant le Code forestier brésilien, les mesures prises par le gouvernements fédéral et de l'Etat du Paraná en ce qui concerne la mise en œuvre des politiques publiques découlants de l'environnement.

Mots-clés: Code Forestier; environnement; les politiques publiques.

Resumen: Esta investigación tiene como objetivo estudiar las políticas públicas relacionadas con el medio ambiente que tiene por objeto la protección de los recursos naturales en cooperación con la sociedad. Por lo tanto, este artículo expone una breve discusión sobre el ajuste del entorno de políticas públicas. Hay también una breve discusión del Código Forestal de Brasil, las medidas adoptadas por el Gobiernos Federal y de Estado de Paraná con respecto a la implementación de políticas públicas derivadas del medio ambiente.

Palabras clave: Código Forestal; políticas públicas; medio ambiente.

\section{INTRODUÇÃO}

A Conferência das Nações Unidas sobre Meio Ambiente e Desenvolvimento, Rio-92, pode ser considerada o marco reflexivo para uma economia ambientalmente menos danosa. Os resultados dessa conferência foram, além da Agenda 21, que se constitui em um extenso plano de ação para o estabelecimento de parâmetros de sustentabilidade, vários tratados internacionais sobre mudança climática e biodiversidade.

Assim, em tempos de globalização, é imperativo que se estabeleçam algumas normas ambientais visando à mitigação dos danos causados pelo consumo capitalista inconsciente, aliado ao crescente acúmulo das elites econômicas e à degradação do tecido ecológico e social. Por

\footnotetext{
1 Universidade Estadual do Oeste do Paraná (UNIOESTE), Cascavel, Paraná, Brasil.

2 Universidade do Vale do Rio dos Sinos (UNISINOS), São Leopoldo, Rio Grande do Sul, Brasil.
} 
conseguinte, reforça-se a necessidade do estabelecimento de políticas públicas de reorientação dos caminhos e significados de bem-estar social.

O poder das corporações, por um lado, e a fraqueza relativa das instituições políticas responsáveis pela proteção ambiental, por outro, podem resultar em desastres quanto às estruturas de governança em que o bem-estar social e a responsabilidade ficam relegadas ao segundo plano. Exemplo disso é o maior desastre ambiental do Brasil, "o caso de Mariana", onde são evidentes a fragmentação institucional e a fragilidade de coordenação que mina a eficácia e a força do sistema.

O estabelecimento de políticas públicas que visam mitigar danos e proteger o meio ambiente representa apenas um passo inicial no que significa de fato sua implementação, como os Códigos Florestais. Muitas vezes, faltam a essas políticas critérios claros de monitoração e avaliação de sua eficácia e eficiência. Tais inconsistências são, geralmente, consequências de diferentes embasamentos filosóficos normativos e da disputa desigual de poder, que parecem usuais no jogo político e institucional quando do estabelecimento de políticas ambientais. Muito embora algumas políticas públicas contenham no seu bojo a possibilidade de resolução de disputas e cumprimento, inclusive de aplicação de multas e outras penalidades, a fragilização institucional e, como tal, o não cumprimento da parte governamental do compromisso impossibilitam a sua plenitude.

O novo Código Florestal, aprovado pela Lei n. 12.651, de 25 de maio de 2012, contém várias providências que devem ser tomadas pelo Estado. No entanto verifica-se, após anos de sua aprovação, que ainda há medidas que não foram implementadas e outras implementadas parcialmente como, dentre outras, a falta de profissionais e estrutura para as instituições que prestam assessoramento aos proprietários rurais, previstas nos artigos 53 e 54 da referida norma legal, o que nos remete a uma reflexão acerca da precariedade de como são estabelecidas e implementadas as políticas públicas ambientais no Brasil.

Assim, este texto está estruturado com base na literatura sobre temáticas de meio ambiente e dividido em três partes: na primeira, há uma breve reflexão acerca da configuração das políticas públicas com enfoque nas políticas ambientais; na segunda parte, foram resgatados os códigos florestais de 1934, 1965 e 2012 e, por fim, foram identificadas as ações e políticas públicas contidas no novo Código Florestal.

\section{POLÍTICAS PÚBLICAS E MEIO AMBIENTE}

Primeiramente, cabe definir o que se entende por política pública. Para isso buscamos significação nas Ciências Sociais que definem política como sendo o mecanismo em que uma ação coletiva pode ser exercida em vista à deliberação e, como política pública, o modo como o comportamento dos agentes públicos pode afetar suas decisões (OUTHWAITE; BOTTOMORE, 2012). A política pública em um estado democrático busca expressar aspirações da sociedade e, nesse sentido, reporta-se aos movimentos sociais a partir de um conflito. A política pública pode ser entendida também "[...] como o conhecimento que busca, ao mesmo tempo, "colocar o governo em ação" e/ou analisar essa ação [...] e, quando necessário, propor mudanças no rumo ou curso dessas ações [...]" (SOUZA, 2006, p. 26). Embora tenham diferentes abordagens, as políticas públicas geralmente assumem uma perspectiva ampla na medida em que o todo é mais importante que a soma das partes, e indivíduos, instituições, interações, ideologias e interesses têm importância, mesmo que em diferentes graus. 
A discussão em torno do tema políticas públicas, instituições, regras e modelos que as governam, ressurgiu nas últimas décadas motivada seja pelo estabelecimento de políticas restritivas de gastos, seja para o estabelecimento de políticas de redistribuição focalizada. Fundamentalmente, devido à maior visibilidade tanto no seu desenho como na sua execução, uma vez que a maioria dos países em desenvolvimento ou com democracias em processo de consolidação, em especial os da América Latina, não possuem coalizões capazes de um desenho que estimule o desenvolvimento econômico e a inclusão social. Assim, segundo Souza (2006), uma nova concepção quanto ao papel do Estado motivou a substituição das políticas keynesianas do pós-guerra por políticas restritivas de gastos, com orçamentos equilibrados e restrições às interferências do Estado na economia com a justificativa de financiar as políticas sociais.

As formulações de políticas públicas tendem a refletir a vontade coletiva dos cidadãos, pelo menos nos governos democráticos, e, ao mesmo tempo, traduzir os propósitos governamentais em ações e resultados efetivos. No entanto, muitas das vezes, um governo democrático se depara com relações utilitaristas pautadas no consumo e em relações de poder que permeiam a apropriação dos bens ambientais. Assim, a eficiência de todo o processo não está ancorada somente na vontade política dos que a praticam, mas baseia-se, fundamentalmente, em contextos socioambientais, culturais e políticos, ou seja, é necessário antes traçar uma estratégia de ação ambiental sustentável a fim de agregar um conjunto de informações circunstanciais, como as forças sociais envolvidas no processo, além de se conhecer profundamente o problema para poder dispor e escolher as medidas mais apropriadas (RUSCHEINSKY, 2010).

É preciso reconhecer a necessária e importante participação da sociedade bem como seu direito de acesso à informação e à oportunidade de se envolver na tomada de decisão. Ademais, é fundamental que se estabeleça uma relação mais equitativa entre governo e sociedade, em um real processo de mútua cooperação na busca por uma integridade ecológica e social. Por outro lado, quando a participação não é exercida visando ao bem-estar social, mas, sim, aos interesses de determinado segmento ou grupo social, e dependendo do grau de sua influência, torna-se complexa a atuação governamental. O mais urgente parece ser "o fortalecimento do espaço público e a abertura da gestão pública à participação da sociedade civil na elaboração de suas políticas públicas" (JACOBI, 2003, p. 315).

No processo de busca e consolidação da discussão em torno da temática ambiental, que é permeada por conflitos, contradições, limitações e pela necessidade de mitigação dos danos ambientais, os profissionais e especialistas almejam a interdisciplinaridade nas políticas públicas e nas instituições de Estado bem como a participação dos diferentes grupos sociais e de populações vulneráveis ou em situação de risco (LOPES, 2006). O objetivo das políticas públicas deve ser sempre a dimensão social (muito embora forças contrárias estejam sempre presentes), e estas devem ser eficientemente administradas para que se possam alcançar os resultados determinados. Sobre isso, Floriano (2007, p. 31) afirma que

[...] iniciativas recentes revelam que a administração pública no país tem tomado o sentido da ampliação e consolidação da cidadania, com articulação de mudanças nas formas de gestão e no próprio conteúdo das políticas públicas, configurando novos processos políticos e novas formas de gestão em que se destaca, como elemento central, a ampliação do elenco de atores envolvidos, incluindo a maior parte das facções da sociedade civil organizada.

Sobre a participação de diversos sujeitos na governança ambiental, Ruscheinsky (2010) comenta que um dos paradoxos da gestão ambiental integrada como mecanismo de democratização 
é explicar como a institucionalização de procedimentos reprime os movimentos ambientais e, ao mesmo tempo, aumenta a desigualdade e a disparidade do poder de decisão. O autor cita como hipótese o fato de que procedimentos democráticos formais não são suficientes para garantir uma gestão ambiental integrada e democrática.

O atual estado de degradação ambiental mostra que haverá grupos da população e ecossistemas que serão prejudicados, por isso a participação da sociedade é enfatizada para não mais aguardar apenas por soluções provenientes do Estado, senão tomar para si a responsabilidade de melhorar seu entorno. É um ato tanto de cidadania como de responsabilidade para com as pessoas e o meio ambiente. A questão do meio ambiente ou "ambientalização" 3 provoca transformações simultâneas no Estado e no comportamento dos indivíduos, as quais são provenientes de fatores como

[...] o crescimento da importância da esfera institucional do meio ambiente entre os anos 1970 e o final do século XX; os conflitos sociais ao nível local e seus efeitos na interiorização de novas práticas; a educação ambiental como novo código de conduta individual e coletiva; a questão da "participação"; e, finalmente, a questão ambiental como nova fonte de legitimidade e de argumentação de conflitos. (LOPES, 2006, p. 36).

Ainda, segundo o autor, o processo de ambientalização diz respeito mais às experiências empíricas de grupos sociais com os problemas ambientais, por exemplo, a poluição urbano-industrial do que com o lado preservado, com a floresta, povos indígenas ou com os camponeses, ou seja, deriva de um processo anterior de devastação da natureza, intensificado com a industrialização e que se tornou uma questão pública ou socioambiental.

Ao longo do tempo, as nações modernizaram suas leis ambientais na tentativa de frear a degradação ambiental e social, provenientes do modo de produção capitalista. Porém, esses encaminhamentos possuem um âmbito largamente conflitivo, cujos avanços e retrocessos são possíveis. A reprodução do capital continua ávida por recursos naturais, esta é a sua racionalidade (raramente cabe à dimensão racional como preservação). Assim, as corporações podem sabotar políticas públicas ambientais, como aborda Acselrad (2010, p. 112)

[...] se não obtiverem vantagens fiscais, terreno de graça, flexibilização de normas ambientais, urbanísticas e sociais, também se "deslocalizam", penalizando, consequentemente, os Estados e municípios onde é maior o empenho em preservar conquistas sociais e ambientais. Ao mesmo tempo, ao escolherem o espaço mais rentável onde se relocalizar (ou seja, aqueles locais onde conseguem obter vantagens fiscais e ambientais), acabam premiando com seus recursos Estados e municípios onde é menor o nível de organização da sociedade e mais débil o esforço em assegurar o respeito às conquistas legais. Ou seja, nesse quadro político-institucional, os capitais conseguem "internalizar a capacidade de desorganizar a sociedade", punindo com a falta de investimentos os espaços mais organizados, e premiando, em contrapartida, com seus recursos, os espaços menos organizados.

A degradação do meio ambiente encontra-se aliada às persistentes injustiças sociais, por vezes vistas como expressão do fracasso de um projeto desenvolvimentista ou decorrentes das relações mercantis. Neste ínterim, a oportunidade da reformulação do código florestal destaca os embates políticos em torno dos conflitos ambientais como uma questão primordial. As lutas

\footnotetext{
${ }^{3}$ O sentido do termo ambientalização utilizado neste texto é o expresso por Lopes (2006, p. 34), que o descreve como "um neologismo semelhante a alguns outros usados nas ciências sociais para designar novos fenômenos ou novas perspectivas de fenômenos vistos da perspectiva de um processo".
} 
socioambientais esboçam alternativas para produção visando ao consumo do mercado interno e à proteção dos bens ambientais. Nesse sentido, Acselrad (2010, p 112) assevera que

[...] as lutas que evocam tais alternativas politizam a questão ambiental e colocam em discussão o modelo de desenvolvimento que articula as diferentes práticas espaciais. Os protagonistas dessas lutas caracterizam-se pela pretensão a resistir à "chantagem locacional dos investimentos" e pela disposição a discutir as condições em que se pretende efetuar a integração das populações locais ao mercado.

Essa nova maneira de ver o mundo, baseado no paradigma ambiental, é por cientistas, pensadores, professores, redes e grupos sociais. O marco político e conceitual constituído pela Rio-92 não foi suficiente para que o status-quo fosse superado, muito embora tenha se estabelecido um reordenamento de prioridades e um elo importante entre os interesses sociais, culturais, ambientais e econômicos. Isto é fundamental de tal forma que Jacobi (2003, p. 327) expõe um jogo de forças em torno das questões ambientais.

A partir de 1992, algumas redes e coalizões se estruturam com o objetivo de enfrentar tanto em nível nacional como regional, conforme os objetivos e questões em pauta, temas críticos que demandam organização, articulação e mobilização. Entram em pauta de forma cada vez mais significativa a discussão do modelo de desenvolvimento, a necessidade do aprofundamento das análises sobre o quadro socioambiental existente, a identificação dos principais impactos ambientais e sociais e a articulação das entidades civis nos planos local e internacional.

O horizonte de análise da temática em tela parece espraiar-se na atenção aos conflitos a respeito das diversas dimensões inerentes e estar sintonizado com a compreensão de que, de fato, o conceito de sustentabilidade, quanto às proposições constantes do código florestal, encontra-se em um terreno de disputas entre interesses distintos e inconciliáveis. Por isso, a narrativa a seguir procura contribuir para a distinção dos atores que se encontram na mesma arena e dos respectivos conflitos em que se envolvem. A quem serve, para que e a quem interessa o discurso ou uma pesquisa com o suposto aporte científico a partir das ciências sociais? Existem limites de um discurso militante, em sua parcialidade e finitude. As ciências sociais não possuem o pendão de multiplicadores de problemas ou soluções para problemas múltiplos e complexos. Cabe, portanto, refletir e despertar também para a vigência de incertezas e riscos imponderáveis. As questões suscitadas pelo debate em torno da renovação do código florestal estão no bojo de um conflito social e ambiental.

\section{OS CÓDIGOS FLORESTAIS BRASILEIROS}

Em meio aos interesses econômicos e geopolíticos do poder da mercantilização da natureza, em 1934, o Brasil teve seu primeiro Código Florestal. À época, o cenário agropecuário brasileiro mostrava que a cafeicultura avançava e substituía a vegetação nativa; a bovinocultura extensiva era desprovida de técnicas ambientalmente adequadas; a atividade florestal baseada no extrativismo, entre outras consequências, levava o pinheiro Araucária angustifólia praticamente à extinção nos Estados do Paraná e Santa Catarina. Essa situação serviu como justificativa para o Estado brasileiro adotar uma proposição mais intervencionista, como pode ser observada no Capítulo I, do Decreto 23.793- Código Florestal de 1934, artigo 1o: "As florestas existentes no

\footnotetext{
${ }^{4}$ Decreto Federal de 23 de janeiro de 1934. Aprova o Código Florestal. Disponível em: <http://www.planalto.gov.
} 
território nacional, consideradas em conjunto, constituem bem de interesse comum a todos os habitantes do país, exercendo-se os direitos de propriedade com as limitações que as leis, em geral, e especialmente este Código, estabelecem".

Uma das maiores preocupações contidas neste Código era a crescente dilapidação do patrimônio florestal enquanto os particulares tivessem livre poder sobre as florestas. Portanto, a partir daquele momento, as florestas, no seu conjunto, passaram a ter uma conotação de interesse da sociedade, independente se estavam em propriedades públicas ou privadas. Outra medida que a legislação aspirava era a obrigatoriedade de que os proprietários de terras mantivessem ao menos $25 \%$ da propriedade de mata nativa, no entanto não estabelecia que tipo de área, se margens de rios ou outras. Além dessas, o Código tinha várias outras dificuldades para a sua implementação, especialmente a questão da resistência e também da inércia do próprio governo. Todavia, provavelmente, a maior fragilidade da legislação esteja retratada na perda da biodiversidade e, como tal, revela que os princípios científicos não se consolidaram à força de protagonista para os códigos florestais brasileiros.

A percepção de que estava em curso a perda da biodiversidade soava como um dos maiores perigos ao futuro da nação e do próprio desenvolvimento. Diante do debate sobre inovação institucional, emerge a demanda para criar uma norma capaz de progredir nas práticas sociais e dar adequada proteção jurídica ao patrimônio florestal brasileiro, de acordo com a Lei n. 4.771/65, ou o Código Florestal Brasileiro, que traz o seguinte texto no artigo 1ㅇ: "As florestas existentes no território nacional, reconhecidas de utilidade às terras que revestem, são bens de interesse comum a todos os habitantes do país, exercendo-se os direitos de propriedades com as limitações que a legislação em geral e especialmente esta Lei estabelecem".

O objetivo era preservar os mais diferentes biomas, sendo que, na Amazônia, 50\% de área das propriedades rurais deveriam ser destinados à Reserva Legal (RL) e no resto do País, a preservação destes é de $20 \%$. A floresta poderia ser desmatada na sua totalidade desde que replantada, ainda que de espécies diferentes ao bioma a que pertencia. No entanto, para Ahrens (2003), a intenção do legislador ao utilizar a expressão "as florestas [...] e as demais formas de vegetação [...]" não permite ambiguidade de interpretação ou outros significados. O legislador refere-se, nesse caso, às florestas nativas excluindo as florestas plantadas, porém as florestas não são mais consideradas em seu conjunto, mas na sua individualidade, em cada propriedade.

Ainda, segundo Ahrens (2003), os avanços conquistados com o Código Florestal de 1965 não foram suficientes para extirpar a percepção utilitarista dos recursos florestais. Foi somente a partir da institucionalização ${ }^{5}$ da Política Nacional de Meio Ambiente, de acordo com a Lei n. 6.938, que a flora passou a ser um bem jurídico ambiental. Assim, as florestas e demais formas de vegetação se constituem como bens de interesse comuns de todos os habitantes, pelo seu valor intrínseco (valor de existência) e, não apenas por seu uso imediato para a espécie humana (valor de uso).

Observe-se que tanto o Código Florestal de 1934 como o reeditado em 1965 obrigavam toda propriedade rural a destinar parte da propriedade para a Reserva Legal. Ocorre que o próprio

br/ccivil_03/Decreto/1930-1949/D23793.htm>. Acesso em: 5 fev. 2016. Art. 2o- Aplicam-se os dispositivos deste Código assim às florestas como às demais formas de vegetação reconhecidas de utilidade às terras que revestem. Art. 23. Nenhum proprietário de terras cobertas de matas poderá abater mais de três quartas partes da vegetação existente, saldo o disposto nos Arts. 24, 31 e 52.

${ }^{5}$ Esta institucionalização remete a disputas pela legitimidade entre diferentes atores sociais, posto que concomitantemente, se instauram diferentes práticas políticas como ambientalmente benignas ou danosas. 
governo, em nome do progresso, ignorava a lei e até incentivava o desmatamento florestal, e os proprietários rurais, incentivados pela inércia, aproveitaram e desmataram suas terras. O Código Florestal de 1965 foi mais brando em relação ao percentual exigido para Reserva Legal, ou seja, houve diminuição da área em 5\% em relação ao Código Florestal de 1934. A exceção foi para a área da Amazônia legal, que elevou o percentual para 50\%. Somente em 2001, com a Medida Provisória 2.166-67, os percentuais passaram a 80\% para as regiões de floresta na Amazônia Legal e 35\% para o cerrado na Amazônia Legal.

Considerando-se que o meio ambiente é um bem comum e essencial à qualidade de vida e, portanto, um direito universal a ser utilizado de maneira ética, é preciso repensar novas relações como meio de vida, conforme argumentam Oliveira e Palácios (2009, p. 506):

[...] só é possível reconhecer uma questão ética quando os afetados por nossas ações estão incluídos entre os objetos de nossa preocupação. Estes podem ser os humanos ou, ampliando um pouco mais, incluímos os animais capazes de sentir dor e, ampliando ainda mais, incluímos toda a vida. Nesse sentido, cada uma dessas grandes correntes da ética ambiental poderá apresentar argumentos diversos para a proteção, mas, sem dúvida, independentemente da corrente, não há o que contestar acerca da finitude dos recursos naturais e da responsabilidade de todas as nações quanto à manutenção do equilíbrio do planeta que permite a vida humana.

A eliminação de restrições e permissões generalizadas que transformam todo proprietário rural em criminoso ambiental e todo servidor público em criminoso por prevaricação emerge o debate pela flexibilização na adoção de políticas ambientais, em especial medidas diferenciadas de acordo com a característica de cada bioma (FLORIANO, 2007). Uma mudança nesse direcionamento ocorreu em 1981, quando foi estabelecida a Política Nacional do Meio Ambiente, que sistematiza propósitos, consolida parâmetros e amplia as iniciativas nas esferas estadual e federal ao considerar a vegetação nativa como um bem jurídico e ambiental. Além disto, tal Política "estabeleceu princípios sobre ações governamentais para manutenção do equilíbrio ecológico; racionalização do uso do solo; planejamento e fiscalização dos recursos ambientais; preservação de áreas representativas; controle e zoneamento; incentivo a pesquisas; recuperação de áreas degradadas, entre outros" (CASTELO, 2015, p. 230).

Em 2012, foi aprovado o outro Código Florestal $^{6}$ (Lei n. 12.651), cuja finalidade é proteger a vegetação nativa com base em uma série de medidas a serem implementadas visando à preservação e restauração da vegetação nativa tanto nas áreas urbanas como nas áreas rurais. Dentre essas medidas, consta a criação de políticas de meio ambiente e de políticas de incentivos econômicos que fomentem não somente a preservação, mas, principalmente, a recuperação do passivo ambiental. Todavia o padrão de argumentação que tem justificado a promulgação do referido código alia-se ao imperativo de desenvolvimento, modernização e atendimento às demandas, similar do que se tem chamado de "modernização ecológica". Esta noção, muito em voga,

designa o processo pelo qual as instituições políticas internalizam preocupações ecológicas no propósito de conciliar o crescimento econômico com a resolução dos problemas ambientais, dando-se ênfase à adaptação tecnológica, à celebração da economia de mercado, à crença

\footnotetext{
${ }^{6}$ Esta medida esteve envolta em amplo debate das forças políticas. "Um certo número de entidades constituiu-se, igualmente, na perspectiva de influenciar diretamente políticas governamentais e o debate legislativo" (ACSELRAD, 2010, p. 105). Todavia, neste caso, a lógica do movimento ambientalista se viu amplamente derrotada.
} 
na colaboração e no consenso [...] recusa regulações políticas; propõe-se a dar preço ao que não tem preço; opõe a lógica dos interesses à lógica dos direitos; tende a equacionar o meio ambiente na lógica da propriedade privada; o "meio ambiente" é visto como "oportunidade de negócios"; o meio ambiente e a sustentabilidade tornam-se categorias importantes para a competição interterritorial e interurbana; para atrair capitais, a "ecologia" e a "sustentabilidade" podem tornar-se apenas um símbolo, uma marca que se quer atrativa. (ACSELRAD, 2010, p. 107, 109-110).

Para efeitos da presente investigação, os sites da Secretaria Estadual de Agricultura e Abastecimento do Estado do Paraná (SEAB) e do Serviço Florestal Brasileiro (SFB) apresentam dados que nos permitem verificar quais políticas foram implementadas no atendimento do novo código florestal, os quais são apresentados no próximo tópico. Foi, também, realizada visita ao Instituto Ambiental do Paraná (IAP), escritório de Cascavel, onde nos foi oportunizada uma explanação acerca das medidas desenvolvidas pelo Estado.

\section{O CÓDIGO FLORESTAL E SEUS DESDOBRAMENTOS}

O Código Florestal de 2012 estabelece que todo imóvel rural deve manter área de cobertura de vegetação, a título de $\mathrm{RL}^{7}$, nos percentuais de $80 \%$ na Amazônia Legal; 35\% na área de cerrado; e 20\% nos campos gerais e nas demais regiões do País. Embora a Medida Provisória 2.166-67/2001 já previsse esses índices, a manutenção significou um avanço em relação ao código anterior. No entanto a Lei passa a permitir o cômputo das APPs conservadas ou em recuperação no cálculo da reserva para todas as propriedades, independente do seu tamanho ou localização. Também permite sua compensação em diferentes regiões no mesmo bioma, todavia "[...] a compensação das RL deixa de exercer as funções eco-hidrológicas na mesma microbacia em que está a propriedade. [...] Nesse sentido, não é aconselhado compensar indiscriminadamente áreas florestais situadas em diferentes posições do relevo" (TAMBOSI et al., 2015, p. 158-159).

Além da flexibilização, excetuam-se dessa obrigatoriedade as propriedades rurais que tinham até julho de 2008 área de até quatro módulos fiscais e que possuam, mesmo que em percentuais menores, remanescentes de vegetação nativa. De acordo com Tambosi et al. (2015), a partir das mudanças em critérios, as alterações do Código Florestal promoveram redução da vegetação protegida em todas as posições do relevo, o que está em contradição com um cenário de aumento da demanda por recursos hídricos e incidência de eventos climáticos extremos.

Dados do Sistema Nacional de Cadastro Rural (SNCR) dos 5,1 milhões de imóveis rurais, mais de $90 \%$ são de até quatro módulos fiscais, os quais alcançam $25 \%$ da área total dos imóveis, o que equivale a 135 milhões de hectares. Se considerarmos a anistia dada pela desobrigação na recomposição da APP para imóveis que suprimiram sua vegetação até 2008, ela atinge cerca de 90\% dos imóveis de até quatro módulos fiscais e os colocam na condição regular para continuar a explorar essas áreas. Assim, perpetuam-se os problemas ambientais das áreas degradadas. Por outro lado, pesquisa feita, em propriedades do Rio Grande do Sul, por Wollmann e Bastos (2016) mostrou elevada incidência de propriedades rurais de até quatro módulos fiscais que atendem

\footnotetext{
${ }^{7}$ De acordo com Tambosi et al. (2015, p. 157) as alterações que resultaram na redução da área de RL e na possibilidade de deslocamento das RL para outras microbacias reduziram a efetividade da vegetação de intervales em prover funções eco-hidrológicas e a possibilidade de utilização dessa vegetação para aprimorar a gestão hídrica e proteger as regiões mais sensíveis da microbacia.
} 
aos requisitos de $\mathrm{RL}$, diferente das propriedades maiores. Há, portanto, indícios de que essa situação é relevante e deve ser levada em consideração quando da formulação de políticas públicas.

Outra alteração significativa do Código Florestal em relação ao anterior está estabelecida no art. 61-A, ou seja, autoriza a continuidade das atividades para as áreas rurais situadas em Áreas de Preservação Permanente, desde que preexistentes a 22 de julho de 2008. Note-se que, ao tempo em que o Código Florestal avança na exigência de maior percentual de área a ser destinada para a Reserva Legal, nas regiões da Amazônia Legal e no cerrado, retrocede-se quando se excetuam as propriedades rurais da obrigatoriedade de recomposição da área desmatada antes de julho de 2008. Ainda Coutinho et al. (2013, p. 253) comentam que

[...] há um longo caminho de adequação de práticas institucionais, conscientização e educação, envolvendo diferentes atores da sociedade (academia, órgãos ambientais, associações e sociedade), para alcançarmos um modelo de desenvolvimento que permita a redução dos riscos e promova a formação de sociedades resilientes.

A Lei n. 12.651/2012 traz uma série de medidas e de políticas de incentivo que devem ser perpetradas pelo governo ou pelos órgãos ambientais a fim de dar efetividade ao novo Código Florestal. No entanto, passados quatro anos de sua aprovação, elencamos as medidas e políticas públicas constantes da referida lei e sua atual situação, ou seja, o que foi de fato implementado e o que ainda resta a ser concretizado por parte do Estado.

\subsection{Medidas adotadas pelo Governo Federal}

A reformulação de uma política requer igualmente um conjunto de novas ações governamentais. A tendência observada de uma ação das políticas ambientais a partir de códigos científicos demanda, em contrapartida, que os movimentos também se especializam em conhecimentos científicos que lhes sustentam os argumentos. Nesse sentido, a tecnocracia estatal é confrontada com outros levantamentos e perícias, e ao setor ambiental da esfera governamental passa a corresponder um leque especialista ou associativo de ambientalistas. Acselrad (2010) entende que se forjam organizações que se caracterizam por funcionarem com redes que ora são correias de transmissão na execução de políticas ambientais, ora estão no aparelho de Estado. Por vezes, tendem a priorizar o pragmatismo da ação eficaz e a adotar práticas pedagógicas de consultoria.

Vinculado ao Ministério do Meio Ambiente, o Serviço Florestal Brasileiro (CFB), criado de acordo com a Lei n. 11.284/2006, é o órgão que, a partir de 2014, assumiu a responsabilidade pela implantação do novo Código Florestal Brasileiro e pela gestão do Sistema Nacional de Cadastro Ambiental Rural (SiCAR). Dentre as principais atribuições do órgão, está o de gestor florestal, emissor de concessões florestais empresariais, gestor do manejo florestal comunitário e do inventário florestal nacional, além de ser responsável pelo cadastro ambiental rural e pelos programas de recomposição e regularização ambiental.

Uma das principais medidas para atendimento ao estabelecido no novo Código Florestal Brasileiro é o Cadastro Ambiental Rural (CAR), cujo Sistema de Cadastro Ambiental Rural (SiCAR) ficou sob a responsabilidade do SFB. Esse projeto consiste em um registro eletrônico obrigatório de todas as propriedades e posses rurais e tem por finalidade integrar as informações ambientais acerca das Áreas de Preservação Permanente (APPs); Áreas de Reserva Legal (RL); das florestas e remanescentes de vegetação nativa; áreas de uso restrito e áreas consolidadas. A base de dados do SiCAR é estratégica para a gestão ambiental e, ainda, para controle, monitoramento e 
combate ao desmatamento de florestas e de outros tipos de vegetação e é fundamental para o planejamento ambiental e econômico das propriedades rurais (BRASIL, 2016).

Segundo o Serviço Florestal Brasileiro (BRASIL, 2016), foram cadastrados, até julho de 2016, 3,67 milhões de imóveis rurais, totalizando $\mathbf{3 8 3}$ milhões hectares. Do total da área prevista por região, o percentual efetivamente cadastrado é: $100 \%$ na região Norte; $67,6 \%$ na região Nordeste; $89,9 \%$ na região Centro-Oeste; $100 \%$ na região Sudeste e 90,3\% na região Sul. Ressalte-se que o prazo para que todos os proprietários rurais efetuassem o cadastro obrigatório, já incluída a prorrogação prevista em lei, findou em 5 de maio de 2016. Sparovek et al. (2011 p. 133) destacam que "a falta de informação abrangente, pública, atualizada e acessível da malha fundiária não se justifica por limitações tecnológicas ou orçamentárias, mas certamente tem forte respaldo político".

Outra medida necessária para atender ao novo Código Florestal está contida no art. 71, e diz respeito ao Inventário Florestal Nacional (IFN), que tem como objetivo avaliar a qualidade e as condições das florestas; monitorar suas mudanças e recolher informações acerca dos recursos florestais brasileiros, tanto de florestas naturais como de florestas plantadas. De acordo com o SFB (2016), o inventário tem por finalidade subsidiar a formulação de políticas públicas de preservação e uso sustentável dos recursos florestais brasileiros. Atualmente, o projeto está sendo desenvolvido em apenas 13 estados da federação e a estimativa é de que os demais estados possam ser incluídos nos próximos três anos, seus dados inventariados e disponibilizados para o público. A partir das ciências sociais, essas desigualdades fazem sentido.

A denúncia da operação desses mecanismos e a construção de capacidade organizativa e de resistência à chantagem de localização serão, consequentemente, instrumentos de pressão pela redefinição das práticas sociais e técnicas correntes de apropriação do meio, de localização espacial das atividades e de distribuição do poder sobre os recursos ambientais. (ACSELRAD, 2010, p. 110).

Embora não tenha sido possível identificar a efetiva implementação ${ }^{8}$ de algumas das políticas contidas no novo Código Florestal, causa apreensão o fato de que as regiões do Nordeste, Centro-Oeste e Sul não atingiram o índice de 100\% das propriedades rurais cadastradas bem como o Inventário Florestal Nacional possua apenas 50\% dos estados abrangidos pelo projeto. De acordo com Tambosi et al. (2015, p. 159), "infelizmente, as mudanças do Código Florestal vêm na contramão do que seria necessário para uma adequada gestão desses recursos". Entende-se que uma política ambiental deva, primeiramente, sofrer atenção do Estado para cumprir com sua parcela de responsabilidade para, depois, legitimar a exigência sobre os demais segmentos envolvidos no processo.

\subsection{Medidas adotadas pelo Estado do Paraná}

Historicamente, a internalização da questão ambiental é o processo de construção política que possui ligação imediata com o perfil da administração pública. Dessa forma, Borinelli (2011), ao abordar as medidas de política ambiental no estado do Paraná, observou que a ação

\footnotetext{
8 Não foi possível identificarmos nas pesquisas bem como não obtivemos resposta até o momento da consulta efetuada junto ao Ministério do meio Ambiente e ao Instituto Ambiental, sobre a efetiva implementação, atualização ou modernização, por parte do Estado, das medidas constantes nos artigos 31, 34, 35, 40, 41, 42, 58,71 e 74 do novo Código Florestal.
} 
governamental nas temáticas ambientais varia de intensidade de acordo com as características próprias dos partidos políticos ou das alianças no poder. Igualmente balançam organizações, atores e empresas, visando exercer a influência nas ações no respectivo campo político, que se reflete diretamente nas medidas ambientais. Isto se traduz em um diagnóstico de instabilidade e de incertezas no direcionamento de um patamar desejado de medidas adotadas pelo setor público em prol da efetivação da legislação ambiental.

Apurou-se, na Secretaria Estadual de Agricultura e Abastecimento (SEAB), que o Estado do Paraná, a partir da publicação do novo Código Florestal, adotou algumas medidas que visam atender ao estabelecido na referida norma legal. Importante iniciativa foi a implementação do Programa de Gestão de Solo e Água em Microbacias, cuja coordenação está a cargo da SEAB, e que tem por objetivo

[...] recuperar e manter a capacidade produtiva dos recursos naturais, com base na gestão de microbacias hidrográficas; melhorar a qualidade de vida das populações rural e urbana dos municípios do Paraná através da promoção de uma agricultura sustentável (ambiental, social, econômica), por meio da gestão integrada dos recursos naturais solo, água e biodiversidade, e reconhecer que o agricultor, ao cuidar das riquezas ambientais do meio rural, se transforma no guardião da qualidade de vida em suas comunidades. (PARANÁ, 2016).

Ainda segundo o referido órgão, esse programa abrange todos os municípios do Paraná, com um total de 400 microbacias. De fato, existem alguns determinantes em face da decisão de manter áreas protegidas em terras privadas, como no caso das reservas legais (MARQUES; RANIERI, 2012). Antes de uma correlação negativa, a largo prazo é possível destacar um encadeamento entre variáveis econômicas e a proporção de áreas protegidas instituídas como reservas legais. Estudos apontam que não se sustentam argumentos utilizados para justificar ou embasar a flexibilização da proteção ambiental.

No projeto das microbacias, cerca de 20.000 famílias são beneficiadas, as quais se espelham em experiências adquiridas no desempenho de programas similares desenvolvidos no Estado nos últimos quarenta anos. Esse programa agregou novas estratégias de abordagem como a

[...] atuação em manejo e conservação do solo e da água em pelo menos uma microbacia em cada município do Paraná; ações integradas de vários programas ambientais, sociais e produtivos, com forte participação popular e base técnica; integração maior com o plano estadual de gestão de estradas rurais, orientando-o em bases conservacionistas; capacitação de prefeituras municipais, assistência técnica e comunidades locais e linhas de crédito para recuperação e manutenção dos recursos naturais. (PARANÁ, 2016).

Além desse programa, outras medidas implementadas pelo estado do Paraná, com vistas à proteção e à recuperação das florestas paranaenses são: i) criação do comitê gestor para o levantamento de florestas plantadas no Estado ${ }^{9}$. Esta é uma exigência do art. 7o do novo Código Florestal, cujo levantamento do inventário florestal deverá produzir os parâmetros fundamentais para o conhecimento das áreas ocupadas pelos diferentes povoamentos e formações florestais; ii) Indicação de nova comissão coordenadora do Zoneamento Ecológico Econômico $(Z E E)^{10}$, exigência do art. 3o do novo Código Florestal. No Paraná, essa comissão já havia sido designada em 2010, sendo reestruturada a partir do novo Código Florestal e, iii) instituição do

\footnotetext{
$\overline{9}$ Resolução SEAB/SEMA n. 11/2012, de 11 de outubro de 2012.

${ }^{10}$ Resolução Conjunta SEMA/ITCG n. 7, de 18 de junho de 2012.
} 
Projeto Parques do Paraná ${ }^{11}$ - conhecer para conservar, que estabelece a gestão estratégica de áreas protegidas, visando à defesa da biodiversidade aliada à educação ambiental. Embora essa medida não seja uma exigência da Lei, ela corrobora com a preservação das florestas, uma vez que seus objetivos são promover o turismo sustentável, bem como a geração de novos negócios, a consciência ambiental e o estabelecimento de vínculos entre comunidades e unidades de conservação ambiental.

\section{CONSIDERAÇÕES FINAIS}

Este artigo buscou apresentar, sucintamente, uma reflexão acerca de como se configuram as políticas públicas, uma breve discussão dos códigos florestais brasileiros e algumas ações levadas a efeito no tocante à implementação de medidas decorrentes. Apurou-se que a configuração e a elaboração de políticas públicas sofrem influências não apenas das contingências sociais relacionadas, mas também de determinados segmentos que se utilizam da estrutura para garantir seus interesses particulares em detrimento dos bens ambientais. Essa situação pode ser presenciada quando da elaboração, discussão e aprovação do novo Código Florestal entre a bancada ruralista que, calcada no discurso da inviabilidade da manutenção da produção agrícola, defendia uma lei mais branda e, de outro lado, os ambientalistas que defendiam bases sustentáveis.

As configurações da cadeia produtiva brasileira, dos recursos naturais e sua (não) preservação, aliadas aos discursos da inviabilidade da pequena propriedade e de segurança jurídica para o agronegócio, foram relevantes no desenho que representa a preservação em relação à $\mathrm{RL}$, por exemplo, um retrocesso para o estabelecimento de um desenvolvimento que considere a dimensão da sustentabilidade. Esse retrocesso pode ser claramente observado pela anistia dada às propriedades rurais que, ilegalmente, desmataram áreas de reserva até 2008 sem a obrigatoriedade de recomposição, claramente uma opção política que menospreza práticas de sustentabilidade. Como podemos observar, o Governo Federal pouco realizou das políticas públicas contidas na referida lei, haja vista o SiCAR e o Inventário Florestal Nacional serem as ações efetivamente realizadas, embora de forma parcial. Não bastasse o retrocesso ambiental em alguns pontos, há que se observar as iniciativas da sociedade em evitar que a lei seja letra morta. A descontinuidade das políticas e a falta de uma visão mais abrangente podem ser determinantes para a configuração ambiental do País.

O Governo do Estado do Paraná adotou novas estratégias e abordagens ao Programa de Gestão do Solo e Água em Microbacias; criou o Comitê Gestor para o levantamento de florestas do Estado; criou a Comissão para Zoneamento Ecológico Econômico (ZEE) e instituiu o Programa Parques do Paraná que, embora não seja uma exigência do Código, é uma iniciativa no sentido da preservação florestal e incentivos à construção de dimensões da sustentabilidade. Cabe reconhecer que são proposições burocráticas diante do fato de que o que está em risco é a maneira efetiva de ser e de governar na sociedade contemporânea. Ao se tentar debelar os efeitos do progresso, fica olvidado que os riscos e as incertezas são a condição social em que navegam tanto governos quanto cidadãos no início do século XXI.

No entanto, dado que o Código aprovado não representa expressivo avanço na efetiva proteção dos recursos naturais, pode-se aferir o grau de interesse e envolvimento dos Governos e da sociedade civil na promoção de práticas e projetos sustentáveis e na proteção dos recursos

\footnotetext{
${ }^{11}$ Resolução SEMA n. 053, de 24 de junho de 2015.
} 
naturais, pela capacidade de implantação, instrumentalização e execução das políticas públicas, programas e projetos, visando dar efetividade à nova norma legal.

Este artigo apresentou uma leitura parcial sobre os desdobramentos da trajetória do código florestal, diante do que podemos concluir o quão distante estamos situados em face do cuidado com a nossa 'casa comum'. Tomando-se como chave de análise a dimensão dos paradigmas em questão, evidencia-se que as ponderações ecológicas e as ações dos governos delimitam uma crise civilizacional tendo em vista as suas referências socioculturais. O setor hegemônico na reformulação desconhece os limites da modernização ecológica, a racionalidade instrumental em que navega, bem como é refratária à crítica do paradigma tecnocrático e do antropocentrismo. Os elementos programáticos para o cenário brasileiro que se elencam e que movem ações governamentais ou da iniciativa privada parecem se conter na política de gestão para a resolução dos impactos socioambientais. Outra dimensão que escapa reporta-se à dimensão da intersetorialidade e da complexidade quando se trata dos conflitos que permeiam as políticas públicas ambientais.

Para finalizar, há outros três aspectos quanto ao imponderável das mudanças em curso: as forças autoras das mudanças em destaque ao se pautarem pela eficiência econômica, desviam o olhar da persistência da pobreza, das desigualdades e da insegurança engendradas conjuntamente com a modernização tecnológica. Os desafios do gerenciamento de uma sustentabilidade ambiental da nova lei desconsideram as consequências de uma sociedade de risco, ainda mais que, por suas características, os danos e perigos por ela produzidos ultrapassam fronteiras. A cultura de consumo, que alicerça de alguma forma as proposições do código florestal, ignora a gravidade dos impactos ambientais, e a sua lógica desconhece as situações de precariedade social. Em outros termos, como consumidores, vorazes ou incautos, possuímos um débito com a reformulação do código florestal e de suas consequências.

\section{REFERÊNCIAS}

ACSELRAD, H. Ambientalização das lutas sociais - o caso do movimento por justiça ambiental. Estudos Avançados, v. 24, n. 68, p. 103-119, 2010.

AHRENS, S. O "Novo" Código Florestal Brasileiro: conceitos jurídicos fundamentais. In: CONGRESSO FLORESTAL, 8. São Paulo: Sociedade Brasileira de Silvicultura; Brasília: Sociedade Brasileira de Engenheiros Florestais, 2003. 1 CD-ROM.

BORINELLI, B. A Institucionalização da Gestão Ambiental nas Empresas e no Governo do Estado do Paraná: etapas, contextos e padrões de relações no período de 1970 a 2006. Relatório Final. Londrina, PR: UEL, 2011.

BRASIL. Serviço Florestal Brasileiro. Inventário Florestal Nacional. MMA. 2016. Disponível em: <http://ifn. florestal.gov.br/>. Acesso em: 10 mar. 2016. Lei Federal n. 12.651, de 25 de maio de 2012. Novo Código Florestal. Brasília: Senado Federal, 2012. 1965. Lei Federal 4.771, de 15 de setembro de 1965. Institui Código Florestal: Brasília: Senado Federal,

CASTELO, T. B. Legislação florestal brasileira e políticas do governo de combate ao desmatamento na Amazônia Legal. Ambiente e Sociedade, v. 18, n. 4, p. 221-242, 2015.

COUTINHO, M. P. et al. O Código Florestal Atual (Lei Federal n. 12.651/2012) e suas implicações na prevenção de desastres naturais. Sustentabilidade em Debate, Brasília, v. 4, n. 2, p. 237-256, 2013.

FLORIANO, E. P. Políticas de gestão ambiental. 3. ed. Santa Maria, RS: UFSM-DCF, 2007. 
JACOBI, P. R. Espaços públicos e práticas participativas na gestão do meio ambiente no Brasil. Sociedade e Estado, Brasília, v. 18, n. 1-2, p. 315-338, jan./dez. 2003.

LOPES, J. S. L. Sobre processos de "ambientalização", dos conflitos e sobre dilemas da participação. Horizontes Antropológicos, Porto Alegre, v. 12, n. 25, p. 31-64, jan./jun. 2006.

MARCONDES, S. Quinhentos anos de legislação ambiental no Brasil. Portal EcoDebate. 2015. Disponível em: <http://www.ecodebate.com.br/2015/07/14/quinhentos-anos-de-legislacao-ambiental-no-brasilartigo-de-sandra-marcondes/>. Acesso em: 4 fev. 2016.

MARQUES, E. M.; RANIERI, V. E. L. Determinantes da decisão de manter áreas protegidas em terras privadas: o caso das reservas legais do Estado de São Paulo. Ambiente e Sociedade, v. 15, n. 1, p. 131-145, 2012.

OLIVEIRA, C. A. de; PALÁCIOS, M. Diferentes abordagens sobre ética ambiental. Caderno de Saúde Coletiva, Rio de Janeiro, v. 17, n., 3, p. 493-510, jul./set. 2009.

OUTHWAITE, W.; BOTTOMORE, T. (Ed.). Dicionário do Pensamento Social do Século XX. Rio de Janeiro: Zahar, 2012.

PARANÁ. Secretaria Estadual de Agricultura e Abastecimento- SEAB/Paraná. Programa de Gestão de Solo e Água em Microbacias. 2016. Disponível em <www.agricultura.pr.gov.br/modules/conteudo/conteudo. php?conteudo=27>. Acesso em: 6 mar. 2016.

RUSCHEINSKY, A. Desigualdades, capital social e desdobramentos dos conflitos socioambientais. In: MELO, José Luiz Bica; LOPES, José Rogério (Org.). Desigualdades sociais na América Latina: outros olhares, outras perguntas. São Leopoldo, RS: Oikos, 2010.

SOUZA, C. Políticas Públicas: uma revisão da literatura. Sociologias, Porto Alegre, ano 8, n. 16, p. 20-45, 2006.

SPAROVEK, G. et al. A revisão do Código Florestal brasileiro. Novos Estudos - CEBRAP, n. 89, p. 111-135, 2011.

TAMBOSI, L. R. et al. Funções eco hidrológicas das florestas nativas e o Código Florestal. Estudos Avançados, n. 29, v. 84, p. 151-162, 2015.

WOLLMANN, L. M.; BASTOS, L. C. Proposição e avaliação de índice de vegetação nativa um recuperar (IVNR) da propriedade rural. Revista Árvore, v. 40, n. 3, p.407-414, 2016.

\section{Sobre os autores:}

Jandira Turatto Mariga: Graduação em Economia pela Universidade Estadual do Oeste do Paraná (UNIOESTE). Mestrado em Engenharia de Produção pela Universidade Federal de Santa Catarina (UFSC). Doutoranda em Ciências Sociais pela Universidade do Vale do Rio dos Sinos (UNISINOS). Pesquisadora Colaboradora do Grupo de Pesquisa em Comportamento Político do Centro de Ciências Sociais Aplicadas, Campus Cascavel. UNIOESTE. E-mail: jandira.mariga@unioeste.br

Aloisio Ruscheinsky: Graduação em Ciências Sociais e em Filosofia pela Universidade do Vale do Rio dos Sinos (UNISINOS), mestrado em Ciências Sociais pela Pontifícia Universidade Católica de São Paulo (PUC-SP) e doutorado em Sociologia pela Universidade de São Paulo (USP). Professor titular do PPG Ciências Sociais da UNISINOS. E-mail: AloisioR@unisinos.br 